\title{
FESTAS: TRADIÇÕES REINVENTADAS NOS ESPAÇOS RURAIS DOS CERRADOS DE MINAS GERAIS
}

- ROSSELVELT JOSÉ SANTOS ${ }^{1}$, MARLI GRANIEL KINN²

\section{RESUMO}

O tRABALHO CORRESPONDE, DE CERTA FORMA, À COMPREENSÃO DE ALGUNS ASPECTOS DO MODO DE VIDA DOS PRODUTORES RURAIS DO VALE DO RIO ARAGUARI, NA REGIÃO DO TRIÂNGULO MINEIRO, NO ESTADO DE MINAS GERAIS. OCUPAMO-NOS DO MODO DE SER DAS PESSOAS, COMO ESSÊNCIA dO PROCESSO DE ESTRUTURAC̦ÃO, FORMAC̦ÃO E TRANSFORMAÇ̃̃ DOS LUGARES COMUNITÁRIOS. POR ESSE CAMINHO, INDAGAMOS A RESPEITO DA DIREÇ̃O, DO SENTIDO E DOS IMPASSES DA MODERNIZAÇÃO E DOS PROCESSOS PRODUTIVOS QUE, AO MESMO TEMPO EM QUE ESVAZIAM OS ESPAÇOS RURAIS, OS ENCHEM DE PESSOAS, DO LUGAR E DE FORA DELE, NOS MOMENTOS DE COMEMORAÇÕES. DESSE MODO, CENTRALIZAMOS AS NOSSAS ATENÇ̃̃ES AO MODO DE VIDA RURAL E ELEGEMOS A FESTA COMO MANIFESTAÇ̃̃ CULTURAL PRIVILEGIADA, SOBRETUdO PORQUE AS COMUNIDADES PERMITIRAM ANALISAR E COMPREENDER, POR MEIO DAS RELAÇ̃̃ES DE VIZINHANC̦A, DE AMIZADES E DA RELIGIOSIDADE, AS REDES SOCIAIS E OS PROCESSOS PELOS QUAIS FORAM SE FORMANDO AS IDENTIDADES E PERTENCIMENTOS AOS LUGARES.

PALAVRAS CHAVES: FESTA - MODO DE VIDA - IDENTIDADE E LUGAR.

No cerrado de Minas Gerais, cerca de $70 \%$ das pessoas, até meados do século $\mathrm{XX}$, viviam no campo. O rural se constituía no mais rico espaço das manifestações culturais e religiosas. Os conteúdos éticos e morais das comunidades e vilas rurais tinham por base a religião católica, que por sua vez propiciava o fortalecimento de diversas práticas sociais, como o mutirão, a ajuda mútua, procissões, festas, dentre outras, as quais permaneceram durante um bom tempo arraigadas ao modo de vida das pessoas, especialmente dos camponeses e dos fazendeiros.
Nos domínios do cerrado mineiro, os produtores rurais viviam em grupos familiares e formaram, em suas relações sociais, comunidades, constituídas por costumes e tradições que adquiriram conteúdos comunitários carregados de significados. Nas unidades de produção rural, as relações entre vizinhos definiram as condições de se obterem produção e produtividade, principalmente na pecuária e na subsistência, e neste processo geraram habilidades, técnicas e compromissos sociais mais ou menos territorializados nos domínios das suas respectivas comunidades. 
No Vale do Rio Araguari, na região do Triângulo Mineiro, o processo de ocupação iniciou-se no final do século XIX, com a chegada de pessoas vindas das minas de ouro e diamante, da região de Ouro Preto e Diamantina. Desde o início da ocupação, a ética e a moral cristã formaram aspectos importantes da cultura imaterial e foram determinantes na construção dos lugares e das comunidades rurais

Sendo a formação religiosa católica um fundamento comunitário, na ausência de templos religiosos, as pessoas foram erguendo os Cruzeiros, os quais acabaram por definir a localização do sagrado. Os espaços onde foram fixados os cruzeiros logo assumiam uma condição de centralidade na vida das pessoas. Dessa forma, os membros das comunidades se dirigiam para esses locais com o objetivo de cumprir com os seus compromissos religiosos.

Nesses lugares e no entorno deles, por iniciativa das comunidades, ergueram-se as capelas; nelas se iniciaram os encontros religiosos e as comemorações dos dias dos santos católicos, principalmente dos padroeiros das comunidades.

A vida em comunidade acabava por gerar lideranças e, com elas, iam-se promovendo acordos, que resultavam no envolvimento dos seus membros com as obras e os eventos comunitários. Capelas, salões de festas, festas, procissões, dentre outros, eram justificados a partir de promessas que se faziam cumprir, em agradecimento às graças recebidas. Como principal obra, as Capelas, geralmente, recebiam o nome do santo padroeiro e se tornaram, desde então, o lugar de práticas religiosas e, por extensão, do encontro e do reencontro das pessoas.
Desse modo, as festas nasceram das iniciativas comunitárias e depois foram sendo ligadas à Igreja Católica. Mais ou menos autônomas, as festas tiveram uma forte presença na organização das comunidades rurais, fato que é por demais evidente, haja vista que o envolvimento comunitário das pessoas ocorre no processo produtivo, principalmente na troca de serviços e produtos que se tornam compromissos fortalecidos durante os encontros comunitários.

Como as relações sociais acontecem em função das necessidades impostas pelo processo produtivo, em momentos posteriores, quando os produtores rurais já se encontravam estabelecidos e fortalecidos pelos acordos comunitários, é que as pessoas começam a se organizar para construir as suas capelas. Portanto, os encontros, em um primeiro momento, aconteceram fora das capelas.

Católicos praticantes, as pessoas da bacia do rio Araguari precisaram resolver os seus problemas imediatos da vida para depois, aos poucos, procurar estabelecer, por meio do religioso, formas de transformar esses encontros em momentos de doações, para então edificar, nos espaços já sacralizados, as suas capelas. Portanto, os encontros comunitários, à época da chegada das primeiras famílias, vindas de outras regiões de Minas Gerais, acontecem antes mesmo da edificação dos lugares sagrados, capelas.

Com a edificação das capelas, elas passam a ser a obra que institui mecanismos facilitadores do controle das pessoas. No entanto, esse caráter controlador não inibiu a realização das festividades, principalmente aquelas demarcadas pelo ciclo da natureza. As festas continuaram e se integravam ao modo de vida das pessoas que, paulati- 
namente, instituíram os seus calendários festivos, tendo como realizadora a comunidade.

Considerada como manifestação cultural, a festa apareceu, nessa parte do cerrado, com uma junção do sagrado e do profano, dando à religiosidade das pessoas um aspecto rústico. Nesta perspectiva, a significação e o sentido das tradições históricas estão relacionadas como aquelas que vêm da religião e das comunidades rurais.

Desse modo, centralizamos as nossas atenções ao modo de vida rural e elegemos a festa como manifestação cultural privilegiada, sobretudo porque as comunidades permitiram analisar e compreender, por meio das relações de vizinhança, de amizades e da religiosidade, as redes sociais e os processos pelos quais foram se formando as identidades e pertencimentos aos lugares. Também, a partir das festas, foi possível analisar as estratégias, os arranjos comunitários, fundamentados em experiências vividas individualmente e em comunidade.

Os objetivos deste trabalho correspondem, de certa forma, à compreensão de alguns aspectos do modo de vida dos produtores rurais do vale do rio Araguari, na suas generalidade, e também como processo específico, que implicou as manifestações culturais e reinvenções das tradições dos grupos sociais.

Neste texto, não abordamos uma festa comunitária. Ocupamo-nos do modo de ser das pessoas, como essência do processo de estruturação, formação e transformação dos lugares comunitários. Por este caminho, indagamos a respeito da direção, do sentido e dos impasses da modernização e dos processos produtivos que, ao mesmo tempo em que esvaziam as comunidades rurais, as enchem de pessoas, do lugar e de fora dele, nos momentos de comemorações.
As localidades comportavam manifestações de autonomia, cujos atributos demonstram tempo, ou contextos históricos diferentes, que são parte de um momento em que as atividades agropecuárias dependiam do auxílio dos vizinhos e familiares. Com isso, as festas surgem como um acontecimento marcado pelo encontro, criação e fortalecimento de uma teia de relações sociais, tendo nos Santos padroeiros seus principais mediadores.

Pensando nas interações entre as festas do passado e os atuais festejos, os quais não são absolutamente independentes, percebemos que a festa rural, no processo de formação das comunidades, funcionava como uma entidade sociocultural muito diversa, portadora de uma identidade que lhe ia sendo atribuída pela objetividade dos processos produtivos, ou seja, do contexto da produção que ia ocorrendo nas fazendas e nas unidades de produção familiar.

\section{Os CONTEÚDOS COMUNITÁRIOS DAS FESTAS}

As festas do cerrado devem ser consideradas como uma manifestação da comunidade, a exemplo das próprias necessidades dos camponeses e fazendeiros, que lhes deram sentido. Todavia, considerá-las assim é uma conceituação cuja especificidade exige que se encontre, paralelamente, por meio da análise de algumas particularidades, a possibilidade de compreendê-las em vários lugares e em diferentes épocas do ano. Ora, as formas como os produtores rurais foram se adaptando ao ciclo da natureza e nele fundindo o seu ciclo agrícola é uma forma de entendimento das festas que permite, ao seu término, a reconstituição dos sentidos das datas comemorativas de cada comunidade. Quanto ao modo de vida, interessa-nos verificar 
as habilidades das pessoas que, em parte, devem poder ser analisadas a partir dos costumes e tradições relacionados à realização das festas tradicionais, nos espaços rurais do cerrado.

Neste sentido, entendemos que a herança cultural dos grupos sociais do cerrado é também marcada pelo costume.

Segundo as argumentações e considerações de (THOMPSON, 1998, p.22)

Os costumes realizam algo - não são formulações abstratas dos significados nem a busca de significados, embora possam transmitir um significado. Os costumes estão claramente associados $e$ arraigados às realidades materiais $e$ sociais da vida e do trabalbo, embora não derivem simplesmente dessas realidades, nem as reexpressem. Os costumes podem fornecer o contexto em que as pessoas talvez façam o que seria mais difícil de fazer de modo direto[...], eles podem preservar a necessidade da ação coletiva, do ajuste coletivo de interesses, da expressão coletiva de sentimentos e emoções dentro do terreno e dominio dos que deles co-participam, servindo como uma fronteira para excluir os forasteiros.

Costumes envolvem articulações de pessoas na realização da festa e representam a legitimação de um modo de ser, manifestado por meio de práticas sociais e de habilidades em se continuar organizando comemorações, eventos, encontros e reencontros, no entorno das tradicionais comunidades rurais.

Sobre as festas, os costumes funcionam como referenciais éticos e morais de um grupo social e, de certa forma, estabelecem princípios e valores para se efetivarem reivindicações, de várias ordens. Para as pessoas que fazem a festa, o envolvimento com os santos tem, nos costumes, o seu referencial de aprendizado.

Nas comunidades rurais, bem antes da revolução verde atingir os cerrados de Minas Gerais (1970), as sabedorias, o saber prático e o conhecimento eram heranças transmitidas entre gerações, tendo nas famílias a sua principal instituição. Em comunidades, as transmissões dos saberes práticos se diferenciavam da educação formal, praticadas nas instituições de ensino.

No núcleo familiar, de forma sofisticada, a transmissão de conhecimento era assegurada pela família e, principalmente, pela presença das mães e das avós. As tradições eram socializadas e reforçadas pela transmissão oral. Tratava-se de um cultivo dos costumes dentro de uma cultura que brotava e se afirmava relacionada ao domínio ideológico do catolicismo rústico.

Desta forma, os costumes das comunidades rurais estavam associados e arraigados às realidades materiais e sociais da vida e do trabalho das pessoas. No que se refere ao trabalho, embora as relações sociais não derivem, simplesmente, dessas realidades, nem reexpressem fielmente as suas tradições, representam uma forma de organização das pessoas, para enfrentarem as imposições sociais. Nessa realidade é que estão estabelecidos os costumes e, como manifestação de uma ordem, estes podem fornecer o contexto em que as pessoas se propunham as resolver e a satisfazer as suas necessidades sociais.

Embora as relações de produção sejam outras, o costume de fazer doação para a festa revela con- 
teúdos de uma prática produtiva que os produtores rurais desenvolviam, para obter uma economia de excedentes $\mathrm{e}$, indiretamente, resultados comunitários que cobravam, efetivamente, a colaboração de todos. Neste sentido, a doação era uma imposição social, que entrava nas relações sociais sob a forma de produtos, tempo e habilidades e acabavam por representar uma forma de incentivar e preservar a ação coletiva.

Desta forma, os papéis de cada membro eram definidos, dentro da comunidade, que desenvolve os seus eventos em nome do costume e das tradições religiosas. As práticas sociais, mediadas pela reciprocidade, revelam uma moral que se encontra presente nas relações sociais e que funciona como um conjunto de normas e obrigações recíprocas, de idéias de grupo social e de bem-estar social $_{i}$ enfim, uma ética a orientar a conduta das pessoas de comunidades com interesses e necessidades semelhantes, relativamente pequenas e integradas.

No caso dos camponeses e fazendeiros do cerrado, a festa era um evento que se ligava aos ritos de fertilidades, pois estava diretamente associada às suas práticas produtivas. No período da festa, os costumes de doar-se para os eventos eram transmitidos por meio da família e da comunidade. Porém, as relações sociais que sustentavam as trocas e doações eram mantidas, principalmente, pela reciprocidade.

Então era assim, eu ajudava o vizinho na precisão dele. O vizinho me ajudava, trocava as coisa me dava uma demão na minha precisão. Se eu não tinba precisão eu não precisava que me ajudasse. Quando era época de festa, as pessoa apresentava as doação e ajudava na preparação (...). Todos parece que tinba mais gana (...). porque era assim que tinba que se. ${ }^{3}$

Na preparação da festa, a participação implicava uma forma de demonstração de envolvimento com as coisas da comunidade. A reciprocidade era uma construção social que representava uma troca necessária, uma sociabilidade forçada, imposta socialmente, em que os sujeitos sociais se viam obrigados a participar dos eventos. Desse modo, a reciprocidade funcionava como um compromisso comunitário que se ajustava às imposições sociais e funcionava como resposta a troca obrigatória e aos compromissos sociais de cada pessoa, para com o grupo social.

Era mesmo assim (...). Aqui em casa todo mundo sabia que tinba que participá na comunidade, mas isso era uma coisa que ninguém vinba na casa e cobrava. Pra falá a verdade quem não ia, os outros não vinba na casa de quem não foi $(\ldots){ }^{4}$

Como manifestação de uma lógica que se opõe ao isolamento, a racionalidade dos camponeses e fazendeiros era manifestada como sendo um acordo tácito, cujo conteúdo e sua substância encontram-se relacionados ao campo da necessidade social das famílias, em construir e manter reciprocidade entre vizinhos. O princípio em jogo é o da imposição social e não o da autonomia. A imposição social é devida a toda e qualquer pessoa, no contexto da construção do mundo rural, que tende a transformar parte do tempo social, dos camponeses e fazendeiros da bacia do Rio Araguari, em tempo comunitário. 
$\mathrm{Na}$ concepção dos produtores rurais, sobretudo do camponês, a comunidade é também força produtiva e se refere à contribuição que cada um pode dar ao conjunto, é a reciprocidade construída por pessoas morais em sua relação com os outros membros dessa comunidade. No espaço rural do cerrado, que estamos examinando, a reciprocidade delimita compromissos entre seus membros, em que as práticas são impostas, pois o que, realmente, precisa ser considerado é a comunidade, a produção e os acordos entre produtores.

Não é uma coisa difícil de se explicá, mais acho que difícil de compreendê e de aceitá. Se eu recebo uma ajuda ninguém precisa me cobrá (...). a gente vê a situação e faz pro outro o que o outro fez pros outro, nem precisa sê pra gente. Então é assim as vez eu nem vo recebê de volta aquilo que eu ajudei, mais se eu ajudo isso já é uma presença, uma coisa de intenção pra gente ficá respeitado. ${ }^{5}$

Se os acordos impõem reciprocidades, isso quer dizer que todos cobram, uns dos outros comportamentos que inibam o descompromentimento de alguns, que podem afetar a todos os membros da comunidade.

\section{O povo sempre participa. Acho que o povo} pensa como a gente. Como não sabe do dia de amanbã então participa da comunidade. Lá a gente tá junto, pode resolvê muita coisa junto $\mathrm{A}$ gente sabe o que acontece com o povo. Se eu fico em casa, fico sem sabê e dai qualquê coisa fica só com os que foi lá. Por isso que participá é gostoso. ${ }^{6}$
Para que possa haver a reciprocidade de um para com os outros, os acordos supõem, também, a construção de um confiança que se contrapõe às incertezas.

Na minha maneira de pensar a gente vive meio desconfiado, nem sempre as coisa vão no rumo que a gente quê, então parece que o povo antigo sabia que ficá sozinbo épior, dai a gente tem que pensa direitinbo e vê quando confia(.. ). A confiança é uma coisa de amizade de gente que a gente conbece. ${ }^{7}$

Esses acordos são constituídos por vizinhos de um mesmo lugar ou que mantêm relações e, possivelmente identidades com os lugares. Desse modo, a confiança no outro se realiza no interior de uma comunidade que é, também, um lugar que se reproduz a partir de relações sociais que podem gerar, entre as pessoas, identidades e pertencimentos.

A confiança gerada no interior da comunidade opera, então, no contexto da identidade. Mas trata-se de identidades que se estabelecem de fato, ainda que envolvam pessoas que estejam clivadas por diferenças econômicas ou sociais.

\section{Então não é com qualduépessoa que a gente pode} fazê compromisso. A gente se junta com pessoa que seja boa, que trabalba, que a gente conbece. O melhor jeito de conbecê uma pessoa é pelo trabalbo dela. Então fica mais fácil a gente confiá e desconfiá da pessoa que a gente conbece e que participa da comunidade. ${ }^{8}$

Entre pessoas que mantêm identidades com um mesmo lugar, o pertencimento é uma construção 
social que implica relações que estabelecem e mantêm vínculos com o lugar. Assim, mesmo que no entorno das capelas não existam moradias, é nos seus pátios que os encontros são realizados e se mantêm repletos de simbolismos religiosos e comunitários.

É bem assim, eu the conbeço, vejo a sua forma de procedê, então vejo que o senhor tem procedência que a gente vê que é boa pessoa que vem na festa, que mostra devoção, respeito com nossas coisas. ${ }^{9}$

As pessoas que, dentro da comunidade, se destacam pelas suas habilidades em fazer as festas e exercitar, a partir dos costumes e tradições, suas identidades e pertencimentos com os lugares, vãose reunindo e estabelecendo vínculos sociais, nutridos pela solidariedade, que tendem a permanecer como motivadores dos encontros e reuniões comunitárias.

Como a maioria das pessoas não vive no entorno das capelas, mas mantêm, entre os seus membros, alguns costumes em comum, estes fornecem as substâncias para que elas se envolvam na organização dos festejos.

Uma coisa importante, a pessoa vem na festa, se dedica, faz as coisa tudo como a gente sempre fez, faz com amor, a gente fica satisfeito com o companbeiro e daí vem os comentário, dai um fica sabendo do outro (...). Pode fazê comentário, mais é de coisa boa. ${ }^{10}$

A socialização dos conhecimentos e habilidades acontece nas reuniões e encontros comunitá- rios. Nesses eventos, o importante, para essas pessoas, é ter condições de administrar seu tempo, sem o que seria difícil preparar de modo mais ou menos autônomo, as festividades na comunidade.

Neste sentido, o costume dessas pessoas de dedicar parte do seu tempo para circular pelos lugares onde acontecem as festas, é uma maneira de preservar o interesse pela comunidade e pelos lugares. Os encontros, como ação espontânea, que vêm do interior dos modos de ser, permitem às pessoas ajustes pontuais e que potencializam a expressão coletiva de sentimentos e emoções, dentro das festas.

Atualmente, os grupos de festeiros são identificados pelas suas habilidades e capacidades de juntar pessoas. Cada grupo de festeiro é caracterizado pela sua dedicação aos festejos. As festas tornaram-se resistentes porque a história oral dessas pessoas é muito presente nos seus falares e remontam a experiências vivenciadas pelos pais e avós.

As práticas sociais que sustentam as festas, oralmente transmitidas e exercitadas, nos espaços dos festejos, revelam, ao mesmo tempo em que expressam, os conteúdos sociais do envolvimento das pessoas com as divindades católicas e como elas foram se tornando protetoras da produção e das pessoas.

O nosso padroeiro é São Sebastião, ele épadroeiro do criador de gado. Então quem mexe com gado acredita no santo. A festa então fica pra gente se encontrá com o povo que mexe com aquilo que a gente trabalha. Mas hoje, também tem as pessoa que só é devota do santo(...). É, não produz gado e nem vive aqui. ${ }^{11}$ 
Como os Santos foram sendo inscritos nas comunidades, os objetivos dos festeiros é a inclusão de pessoas devotas dos padroeiros nos preparativos dos festejos. Na verdade, são rituais que tendem a permanecer e a se reproduzir baseados na religiosidade e, também, na inclusão das crianças.

Neste particular, a inclusão das crianças parece gerar certezas em relação à continuidade das festas comunitárias. A introdução da criança é pensada e a sua presença se efetiva como sendo parte importante do modo de ser das pessoas, bem como das suas estruturas morais e éticas. Nesse processo, cabe aos pais fornecer aos seus filhos, desde a mais tenra idade, os conteúdos e as formas que, no cotidiano, realizam-se, articulam-se, ou se confrontam entre grupos sociais, cuja função é a de promover sociabilidades a partir do vivido das pessoas envolvidos com os festejos. Seguramente, trata-se de transmitir, às crianças, conhecimentos históricos, idéias, habilidades, as quais continuam influenciando e transformando a consciência e os processos que redefinem os festejos e as relações com as vizinhanças, os lugares, os grupos sociais e as festas rurais.

\section{REINVENTANDO COSTUMES E TRADIÇÕES}

Agir, para continuar com as festas, significa juntar pessoas e negociar espaços, bem como uma forma de manutenção das características religiosas, dos rituais e das procissões, que implicam tradições, e costumes no uso de vários conteúdos culturais.

Uma festa com leilão é bem uma festa, daquelas do tempo antigo. Sabe, com leilão festa fica com emoção. A pessoa doa um bezerro é dela, foi ela que criou, é da sua fazenda. Então ela doa o seu produto. Se for pra ela dá dinbeiro ela não doa porque tem que fazê o bezerro em dinbeiro. Então precisa da prenda pra sai leilão. É um costume, uma felicidade, é coisa da gente, da família, dos antigo. ${ }^{12}$

O grupo social, enquanto coletividade que se constitui nos encontros, que reafirma costumes e faz questão de trazer prendas para os leilões, os quais dividem tempo e espaço com os bailes da comunidade, é soma de conteúdos culturais, esforços individuais e comunitários, que vão se confirmando na reciprocidade entre pessoas que acreditam umas nas outras, mesmo que elas vivam em espaços de vários lugares.

$$
\begin{aligned}
& \text { A gente vem na festa preparado. A gente traz as } \\
& \text { prenda. Com o leilão a gente sabe que vai arre- } \\
& \text { cadá fundo pra ajeitá a capela e fazê a despesa } \\
& \text { da festa. Então o que a gente continua fazendo } \\
& \text { é uma doação pra que a gente continue tendo um } \\
& \text { lugar pra se reuni e se diverti. }{ }^{13}
\end{aligned}
$$

Se, no passado, a festa era para que as pessoas reatassem os seus acordos, os quais estavam fortemente relacionados à produção, neste momento eles também estão relacionados ao lazer o qual depende da manutenção e reprodução dos lugares comunitários. Desse modo, entendemos que os costumes e as tradições de se fazer a festa, necessariamente, não precisam apresentar uma continuidade com o passado.

Hoje o povo não mantém tudo como era antigamente, nem dá pra gente fazer as coisa que o 
povo fazia. A pessoa que não vive na roça, não deixa de trazê a sua prenda, mas ela traz uma coisa que não é daqui. A gente aceita é bom, mas é diferente. O povo e nem as prenda são de antigamente. ${ }^{14}$

A festa, nos domínios da comunidade, entre outras visões, é explicada por situações que implicam a suspensão das distâncias entre as pessoas, na produção de um estado de efervescência coletiva e nas maneiras com que os grupos sociais transgridem as normas comunitárias. Trata-se de uma capacidade de juntar, no grupo, pessoas identificadas por meio das práticas sociais e relações de troca, que se transformaram em costumes, e que continuam acontecendo, lastreadas pela reciprocidade. Nos leilões, a reciprocidade aparece constantemente, e pouco importa se nela está implícita uma doação simplória ou descontextualizada. O importante sempre foi o gesto, mesmo que seja como irreverência que se opõe às diferenças sociais. A reciprocidade, que opera no interior da família ou de outras instituições sociais, aparece nas festas como tradição porque ela, sendo um ato simbólico, é também um costume.

A doação é aquilo que eu dôo e se eu dôo éporque não vai me fazê falta(...), vai me fazê bem. Eu tenho uma coisa que eu avalio que pode sê importante pra outra pessoa, eu então faço uma doação pra comunidade. Quando a gente doa, o festeiro não precisa sai pedindo e o que ele arrecada serve pra gastá com as obra da comunidade. ${ }^{15}$

O costume de trazer doações atravessa gerações e vai-se concretizando como prática que se preserva, em que os bens arrecadados se transformam em fundos para as capelas e comunidades e repercutem, no grupo, como uma conquista, o que leva as pessoas a se reconhecerem como aceitas no lugar e participantes de uma rede social que contribui para a remoção e/ou amenização de várias carências sociais, tais como: tempo, espaço, lazer, segurança, dentre outros. Como o costume de fazer doação é também uma exposição, um momento em que a doação é leiloada, o doador se sente importante, pois o leilão é um momento em que todos avaliam, admiram, contemplam, disputam o envolvimento das pessoas com a comunidade, ao mesmo tempo em que assistem a ele.

$$
\begin{aligned}
& \text { A festa éassim, reune o povo, cria um envolvimento } \\
& \text { com as coisa que a gente gosta(...). Então se a gente } \\
& \text { gosta daquilo que faz e faz bem feito, o povo vai } \\
& \text { e aceita, acredita no que a gente fez e continua } \\
& \text { vindo e trazendo coisa pra comunidade. }
\end{aligned}
$$

Portanto, recorrer a tais fundamentações cria expectativas de encontrar, nas festas rurais, um movimento que não nega o passado, nem o repete. Em verdade, os encontros continuam, mas continuam fundamentados em costumes e tradições que sofrem, a todo o momento, adaptações, ajustes, rejeições e inclusões, as quais estão diretamente relacionadas aos novos comportamentos das pessoas que já não têm mais os seus tempos vinculados aos ciclos determinados pela produção agropecuária, mas ao tempo e ao espaço decorrentes da vida urbana.

No universo que estamos examinando, a tradição evoca o passado, delimita um campo específico, que passa a ser revisto pela comunidade, prin- 
cipalmente na prática dos eventos. Nesse embate, institui-se uma reflexão, tomando por referência aquilo que é permitido ou reprovado.

Como o povo não vive na roça, fica difícil cobrar deles a prenda da roça. Então boje o povo aceita mais o pessoal da cidade. Mas a maioria são pessoa que era daqui e foi vivê na cidade(...), então quem gosta volta pra festa. Os da cidade, são também daqui, são da casa e quando traz os outro já traz sabendo que vai partipá daquilo que a gente faz. ${ }^{16}$

No momento do sagrado, a comunidade tenta, mas nem sempre consegue, cobrar de toda e qualquer pessoa respeito aos seus costumes e tradições. O ritual envolvendo as santidades, entre os visitantes, nem sempre é seguido à risca, demonstrando que é preciso ser tolerante com aqueles que, por não conhecerem os seus costumes e tradições, acabam promovendo estranhamentos e desconfortos.

$\mathrm{Na}$ concepção dos festeiros, o comportamento de trazer mais gente para um determinado festejo, sem ter cuidado com os rituais, nem sempre é tomado como sendo uma afronta às tradições. A festa se refere à manifestação de costumes e tradições que se expressam como um processo que adota, como referência, a reciprocidade na reinvenção das tradições. Desse modo, os novos comportamentos não se desvinculam do respeito aos que fazem a festa e aos devotos dos padroeiros comunitários.

Isso aqui é antigo, vem lá do tempo do meu avô (...). É uma tradição de família, a gente foi criado nesse sistema de respeitá os que bomena- geia os santo e quando chega a vez da gente fazê a devoção a gente espera participação do povo. ${ }^{17}$

A devoção, muitas vezes, ocorre sobre aspectos característicos de uma santidade. Dependendo da situação, há momentos em que a devoção se redefine, a ponto de criar acréscimos e ou reduções aos rituais, incluindo, minimizando ou retirando homenagens a um determinado Santo. As mudanças ocorrem no interior das comunidades e aparecem, nos espaços dos festejos, como uma adaptação, pois, em certos casos, era tradição homenagear um santo por data. Como há carência de tempo e isso atinge a todos, as festas passam a homenagear, praticamente, todos os santos de uma comunidade, de uma só vez.

Embora os festejos aconteçam uma vez por ano, mais especificamente durante a data do padroeiro, é neste momento que todos são observados. Quando os festeiros e devotos estão fazendo suas louvações aos Santos, nas festas, existem momentos em que a tradição se impõe e, em comum acordo, não mais do que três santos passam a ser homenageados, em uma mesma data.

\section{Isso de bomenagear dois santo de uma vez não era comum. Mas isso acontece porque a gente não consegue fazê tanta festa e reuni o povo. As pessoa não vive mais aqui, o povo tem compro- misso na cidade. ${ }^{18}$}

Juntar vários santos é permitido, pois o uso do mesmo evento é negociado e tende a superar algumas carências, principalmente de tempo e espaço. Na tradição das festas populares, quem louva os santos tem esse momento respeitado, mesmo que o ritual seja dividido com outra santidade. 
Portanto, no dia da festa, quando os devotos de vários santos se juntam, em um mesmo espaço comunitário, geralmente no pátio da capela, as tradições passam a ser adaptadas e este processo, nem sempre, significa romper com as tradições.

A adaptação dos costumes é uma forma que os devotos encontram para realizar algo importante em relação ao sagrado, pois quando eles promovem reformulações, também anunciam outras questões, que estão relacionadas ao modo de vida das pessoas. Neste sentido, é preciso compreender as práticas sócio-espaciais dos devotos, pois as pessoas que fazem os rituais vivem em vários lugares, inclusive na cidade.

O povo vive mais na cidade, eles vêm pra festa. Alguns têm fazenda, sítio (...). Agora eles são parente, amigo, filho, neto dos antigo morador, então nóis gosta da festa da roça e aqui tem uma coisa que deixa a gente emocionado. ${ }^{19}$

A história dos festejos e manifestação de pertencimento aos lugares é singular, pois o espaço a que pertencem não representa uma única totalidade sócio-espacial. Sendo assim, as representações, nos espaços comunitários, não estão isoladas das experiências do vivido, ou seja, se é preciso fazer algumas adaptações, para manifestar as suas devoções aos Santos, as pessoas vão redefinindo as suas posições e recriando os festejos, levando em consideração a lógica que concebe a vida urbana.

As festas rurais são uma manifestação social que continua existindo nas comunidades, pois a essência está na sua capacidade de adaptação das tradições, e provavelmente vão exercer influências nos lugares e nas identidades de seus praticantes.
Antes o povo vinba montado, vinba todo mundo com os animal, o cerrado ficava cheio de carroça. Ficava uma semana acampado, trazia mantimento. Hoje quando venho pra festa aqui na roça, me sinto diferente. Parece que a gente volta no tempo, a gente fica lembrando as coisa lá da nossa meninice. (...) parece que a gente se sente criança correndo atrás de foguete. ${ }^{20}$

Desse modo, os costumes não são formulações abstratas e dissociadas das práticas e significados sociais, nem desvinculados do modo de ser das pessoas. Mesmo que as adaptações estejam resultando na continuidade das festas, os eventos não juntam apenas pessoas, mas geram possibilidades de, nos encontros, redefinirem as identidades e pertencimentos aos lugares. Dessas situações podese entender que se trata, mais do que de uma adaptação, de algo que está posto como desafio para as tradições, mas que dificilmente representará ameaças insolúveis para os seus participantes continuarem com os seus encontros.

Claro está que a urbanização atingiu as comunidades rurais, que os desencontros ocorrem, principalmente quando estes são promovidos por aqueles que não conseguem entender que as tradições também sofrem redefinições e que estas, dependendo das transformações sócio-espaciais, são rapidamente reinventadas, possivelmente continuando a gerar outros tipos de sentimentos e pertencimentos com os lugares onde se realizam os eventos. Com relação ao costume de reunirem-se em datas marcadas, este revela, também, a forma com que as pessoas realizam o uso dos espaços comunitários.

A partir das argumentações de Hobsbawm (1985, p.23), é possível perceber por meio dos 
processos sociais as contradições que movimentam as invenções das tradições:

Espera-se que as invenções de tradições ocorram com mais frequiência: quando uma transformação rápida da sociedade debilita ou destrói os padrões sociais para os quais as velhas tradições foram feitas, produzindo novos padrões com os quais essas tradições são incompatíveis; quando as velhas tradições, juntamente com os seus promotores e divulgadores institucionais, dão mostras de baver perdido grande parte da capacidade de adaptação e da flexibilidade, ou quando são eliminadas de outras formas. Em suma, inventam-se tradições quando ocorrem transformações suficientemente amplas e rápidas tanto do lado da demanda quanto do lado da oferta.

Mesmo que os costumes e tradições estejam sendo redefinidos, no interior das comunidades rurais, esse movimento indica que a vida urbana e as formas de fazer a festa, no rural, fizeram com que aspectos da solidariedade e da reciprocidade comunitária prevalecessem entre seus membros.

A gente faz a festa, porque é a nossa vez. A festa do ano passado foi feita por outras pessoa. O grupo dedicô e a festa saiu, juntô o povo, ganbô as coisa, todo mundo ajudô e nóis aproveitô tudo que o festeiro feiz, então quando chega a nossa vez, a gente vai também recebê dos outro ajuda e fazê do melhor jeito que dá. ${ }^{21}$

A reciprocidade entre as pessoas cria tolerâncias e um sentimento de envolvimento, participa- ção e solidariedade. Desse modo, as festas rurais tendem a ser marcadas pela negociação e não apenas pela fartura e pela doação. Essa reciprocidade pode ser analisada como um costume que se manifesta e se fortalece em um ambiente em que manter-se próximo dos membros das comunidades vem, seguramente, de uma necessidade social, decorrente das atividades rurais, em um tempo em que a reciprocidade era também uma imposição social.

Neste momento, as dificuldades existentes não se resolvem imediatamente no lugar, são também negociadas com os que vivem fora dos lugares comunitários. Na perspectiva dos festeiros, garantir a realização dos festejos implica considerar a organização comunitária, a ajuda mútua, a reciprocidade e a doação, principalmente de tempo e de saberes, de cada pessoa. Tudo isso torna-se uma garantia para que continuem com os seus eventos.

Por tais razões, entendemos que as comunidades rurais, sem dúvida, eram poderosas instituições que se organizavam por meio de uma ordem moral, de valores éticos, os quais faziam com que elas mantivessem vivas as suas identidades com o lugar e com cobranças de reciprocidade, naquilo que era comum a todos.

Desse modo, na perspectiva das rupturas comunitárias ou do grupo social com os costumes de se fazer a festa, entendemos que quando se rompe com certas práticas tradicionais, nem sempre se está rompendo com as tradições, pois precisamos lembrar sempre que as tradições também são reinventadas.

As reinvenções das tradições, a partir das festas rurais, seguramente desempenham um papel para a continuidade das comunidades rurais. A partir 
de suas organizações formais, as pessoas cultivam a necessidade de agir coletivamente e, neste processo do coletivo, percebem a importância de negociar os espaços comunitários, principalmente quando conseguem juntar, no processo de fazer a festa, pessoas de vários lugares.

A capacidade de convivência dos membros das comunidades com as pessoas de fora do lugar, relação que vem-se apresentando nos festejos, tem revelado várias habilidades, dependentes, porém das possibilidades de negociações anunciadas a partir do prestígio político que os festeiros e festejos assumem, em relação à comunidade. Desse modo, relacionar-se com as pessoas de diversos lugares não significa um peso, uma dificuldade ou mesmo uma imposição, para os festeiros.

A partir das comunidades rurais da bacia do rio Araguari, consideramos que as negociações comunitárias promovem arranjos e estratégias sociais e é por meio delas que as pessoas continuam fazendo, das festas rurais, uma tradição reinventada. Aprendemos, também, que os processos de formação destes lugares revelam um dinamismo de práticas sociais que propõem objetivos e sentidos fundantes, que vão-se tornando suporte do modo de vida das pessoas. Na verdade, as festas rurais apresentam um movimento, seguramente dialético, que resulta das transformações das suas práticas sociais, as quais se movem apresentando desencontros em relação à substância do espaço rural. Por isso, é possível entender que, nas festas rurais, há um relacionamento comunitário implicado no movimento próprio da forma sócio-espacial dos lugares, bem como dos conteúdos culturais reeditados nos festejos.

\section{Notas}

1 Professor e pesquisador do Instituto de Geografia da Universidade Federal de Uberlândia.

2 Professora - Mestre em Geografia Humana pela Universidade de São Paulo - USP.

3 Nas transcrições das entrevistas optou-se por respeitar os falares dos entrevistados. Pesquisa de campo - comunidade do Salto - Araguari - MG - Junho de 2005

4 Pesquisa de campo - comunidade do Fundão - Araguari MG - Junho de 2005.

5 Pesquisa de campo - comunidade de Martinésia Uberlândia - MG - Novembro de 2005.

6 Pesquisa de campo - comunidade de Martinésia Uberlândia - MG - Novembro de 2005.

7 Pesquisa de campo - comunidade do Salto - Araguari MG - Junho de 2005

8 Pesquisa de campo - comunidade do Fundão - Araguari MG - Junho de 2005

9 Pesquisa de campo - comunidade do Salto - Araguari MG - Junho de 2005

10 Pesquisa de campo - comunidade do Cruzeiro dos Peixoto - Uberlândia - MG - Junho de 2006.

11 Pesquisa de campo - comunidade do Salto - Araguari MG - Junho de 2006.

12 Pesquisa de campo - comunidade do Fundão - Araguari MG - Junho de 2006

13 Pesquisa de campo - comunidade do Salto - Araguari MG - Junho de 2005

14 Pesquisa de campo - comunidade de Martinésia Uberlândia - MG - Novembro de 2005.

15 Pesquisa de campo - comunidade de Martinésia Uberlândia - MG - Novembro de 2005.

16 Pesquisa de campo - comunidade do Martinésia Uberlândia - MG - Novembro de 2005.

17 Pesquisa de campo - comunidade do Martinésia Uberlândia - MG - Abril de 2006.

18 Pesquisa de campo - comunidade do Fundão - Araguari MG - Junho de 2006

19 Pesquisa de campo - comunidade do Fundão - Araguari MG - Junho de 2006

20 Pesquisa de campo - comunidade da Tenda - Uberlândia - MG - Maio de 2006

21 Pesquisa de campo - comunidade do Cruzeiro dos Peixotos - Uberlândia - MG - Novembro de 2005.

BIBLIOGRAFIA

BORDIEU, Pierre. A Economia das Trocas Simbólicas. São Paulo: Perspectiva, 1974

FERNANDES, Florestan. Comunidade e sociedade: leituras sobre problemas conceituais, metodológicos e de aplicação. São Paulo: Editora Nacional e Editora da USP.1973.

Hobsbawm, Eric. Invenção de Tradições. Rio de Janeiro: Paz e terra, 1985

THOMPSON, E.P. Costumes em comum. São Paulo: Companhia das Letras, 1998. 


\section{ABSTRACT}

THIS RESEARCH STUDY ANALYZES SOME ASPECTS OF THE WAY OF LIFE AND CUSTOMS OF THE AGRICULTURAL PRODUCERS OF tHE ARAGUARI RIVER VALLEY IN THE REGION OF THE TRIÂNGULO MINEIRO, WHICH IS A REGION LOCATED IN THE STATE OF MINAS GERAIS, BRAZIL. THE RESEARCH STUDY SPECIFICALLY ANALYZES THEIR BEHAVIOR AND HOW IT PLAYED A VITAL ROLE IN THE PROCESS OF STRUCTURING, FORMING AND TRANSFORMING THE COMMUNITY. MOREOVER, THE RESEARCH STUDY ALSO EXAMINES THE DIRECTION IN WHICH MODERNIZATION IS GOING AND HOW IT HAS EMPTIED THE RURAL AREAS, BUt FILLED IT UP WITH PEOPLE DURING tHE YEARLY CELEBRATIONS. IN VIEW OF THAT, THE RESEARCH FOCUSES ON THE RURAL WAY OF LIFE, IN ADDITION TO SELECTING THE CELEBRATIONS AS A PRIVILEGE, FOR THE REASON THAT THESE CELEBRATIONS GIVE THE COMMUNITY AN OPPORTUNITY TO ANALYZE AND COMPREHEND THROUGH RELATIONSHIPS WITH NEIGHBORS, FRIENDS, AND RELIGIOUSNESS, THE SOCIAL NETWORKS AND THE PROCESSES BY WHICH THE IDENTITY AND BOND TO PLACE WAS CREATED.

KEY WORDS: CELEBRATION - WAY OF LIFE - IDENTITY AND PLACE 